$$
\begin{array}{cc}
\text { Berechnet für } & \text { Berechnet für } \\
1 / 5\left(\mathrm{Th}_{5} \mathrm{H}_{4}\left(\mathrm{C}_{2} \mathrm{O}_{4}\right)_{12}+25 \mathrm{H}_{2} \mathrm{O}\right) & 1 / 2\left(\mathrm{Th}_{2} \mathrm{H}_{2}\left(\mathrm{C}_{2} \mathrm{O}_{4}\right)_{5}+9 \mathrm{H}_{2} \mathrm{O}\right) \\
\mathrm{n}=5 & \mathrm{n}=2 \\
534,4 & 534,4
\end{array}
$$

Obgleich die Resultate der Versuche die erste Formel als die richtigere anzeigen, neige ich mich doch zur Annahme der zweiten, da die unvermeidliche Correctur keine absoluten Resultate ergeben hat.

Wenn diese letztere Formel die richtige ist, haben wir ein halbsaures Oxalat, in welchem noch beträchtliche Mengen Wasser (9 Molecüle) enthalten sind, die bei $115^{\circ} \mathrm{C}$. nicht ausgetrieben werden.

Baltimore, 1897.

\title{
Eine kleine Spritzflasche.
}

Von

Jos. Loczka.

Es kommt in chemischen Laboratorien täglich vor, dass Niederschläge mit den verschiedensten Flüssigkeiten ausgewaschen oder auf dem Filter gelöst werden sollen. Es ist sehr umständlich für jede dieser Flüssigkeiten eine Spritzflasche in Bereitschaft zu halten oder eine und dieselbe Spritzflasche, je nach Bedarf, für eine andere Flüssigkeit zu reinigen und auszuwaschen. Ich construirte nach dem Muster bekannter Tropfgläser aus einer Eprouvette eine obigen Zwecken sehr entsprechende Spritzflasche, von welcher man sich eine grössere Anzahl verschafft oder selbst anfertigt und in einem Eprouvetten-Stativ aufstellt. Das kleine Geräth hat sich während jahrelanger Benutzung sehr gut bewährt.

Die Benutzung des Geräthes ist zwar selbstredend, ich halte es aber für zweckmässig hinsichtlich der Handhabung desselben Einiges beizufügen. Zur Veranschaulichung dient Figur 1. Das Anfüllen geschieht dadurch, dass man die Spitze $b$ in die Flüssigkeit steckt und bei a entweder mit dem Mund oder mit einer Pumpe saugt, bis die Flüssigkeit bis c gestiegen ist. Muss die Flüssigkeit in dem Geräth aufgekocht werden, so ist es rathsam dass die Oeffnung a nicht dem Körper zugekehrt sei, denn beim plötzlichen Aufwallen tritt die Flüssigkeit öfters bei a heraus und bespritzt den Arbeitenden. Neigt man 
das Gefäss, so tritt die Flüssigkeit tropfenweise bei $b$ heraus. Bläst man in geneigter Stellung des Geräthes bei a hinein, so kann auch ein Strahl auf den Niederschlag geführt werden. Hat man eine genügende Menge Flüssigkeit herausgespritzt, so lässt man mit dem Blasen allmählich nach und bringt die Spritzflasche, a noch immer im Mund haltend,

Fig. 1.

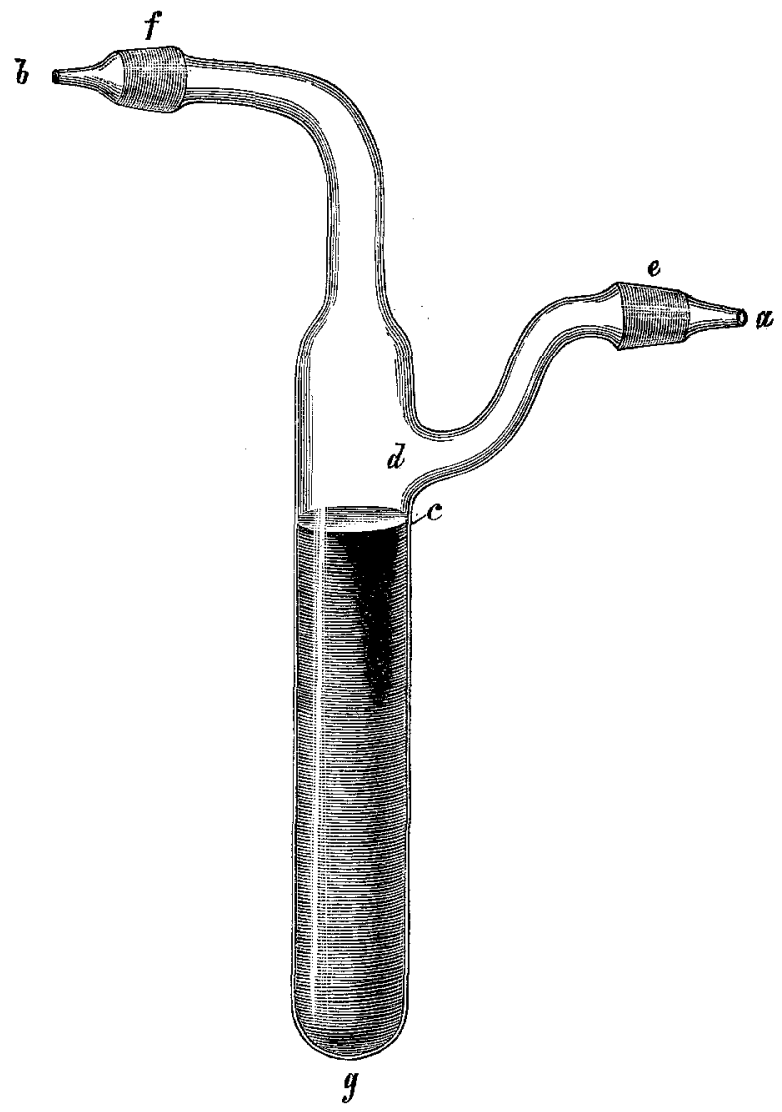

in die verticale Lage, bis die Flüssigkeit $d$ nicht mehr absperrt; ohne diese Vorsicht könnte bei unvorsichtigem Blasen und raschem Aufhören die Flüssigkeit in Folge des Druckes in den Mund treten. Bei e und $f$ werden abgeschliffene Kappen aufgesetzt. Es können Fälle vorkommen, wo man die Menge der verbrauchten Waschflüssigkeit kennen muss, 
dieser Anforderung kann dadurch entsprochen werden, dass das Gefäss von $\mathrm{g}$. bis $\mathrm{c}$ in Cubikcentimeter getheilt wird.

Soll das Gefäss ausgewaschen werden, so bläst man bei a mit der Spritzflasche einige Cubikcentimeter Wasser hinein, schwenkt in horizontaler Lage gut um und lässt das Wasser bei $b$ ausfliessen, diese Manipulation wiederholt man einigemal. ${ }^{1}$ )

Budapest (Museum).

\section{Abdampftriehter.}

Von

\section{Dr. S. Bošnjaković.}

In meinem Laboratorium wird bei verschiedenen Bestimmungen der in Figur 2 und 3 abgebildete Abdampftrichter mit Vortheil

Fig. 2.

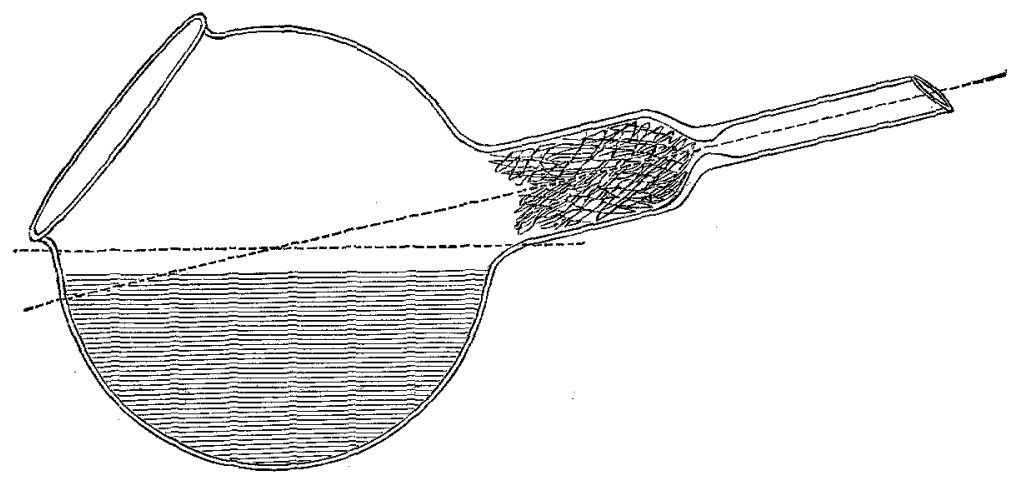

verwendet, und zwar wo man einen direct gefällten Niederschlag oder einen Abdampfrückstand durch Asbest oder Glaswolle za filtriren und zu wägen hat. Es entfällt die oft mit Umständen verbundene Uebertragung des Niederschlages, beziehungsweise Rückstandes, aus einem Gefäss in den Trichter.

1) Dieses Gefäss verfertigt $\mathrm{Nr}$. Karl Kiss ,Glastechnisches Laboratorium“ in Budapest, Esaterházy-Gasse No. 1. 